\title{
Balloon-Assistance for the Transcirculation Access of a Remodeling Balloon for Coiling of Wide-Necked Aneurysms: Report of Two Cases
} \author{
Chaitanya S Juluri, DNB, IDCCM, EDIC 3 , Karuppannaswamy Madeswaran, M.Ch ${ }^{4}$ \\ ${ }^{1}$ Department of Neurointerventional Radiology, Royal Care Super Specialty Hospital, Coimbatore, India \\ ${ }^{2}$ Department of Neurology, Royal Care Super Specialty Hospital, Coimbatore, India \\ ${ }^{3}$ Department of Critical Care Medicine, Royal Care Super Specialty Hospital, Coimbatore, India \\ ${ }^{4}$ Department of Neurosurgery, Royal Care Super Specialty Hospital, Coimbatore, India
}

Madan Mohan Balaguruswamy, MD, PDCC ${ }^{1}$, Ezaz Mohamed, MD, FRCR ${ }^{1}$, Krishnan Vijayan, MD, DM²,

\begin{abstract}
Balloons are valuable tools in the armamentarium of a neurointerventionist. In this report, we describe 2 cases in which a balloon aided in the navigation of a second remodeling balloon through difficult vascular anatomy. The first case was a patient with a ruptured proximal posterior inferior cerebellar artery aneurysm and the second case was a patient with a ruptured anterior communicating artery aneurysm. In both cases, the coiling microcatheter and the remodeling balloon catheters were advanced through different vessels. The remodeling balloon reached the target location using a transcirculation approach, and the navigation of the remodeling balloon was aided by utilizing a second balloon. Challenging vascular anatomy is often encountered when performing neuroendovascular procedures. The strategy of using balloon assistance for the transcirculation access of a remodeling balloon can be used successfully in difficult situations to manage complex aneurysms.
\end{abstract}

Key Words: Intracranial aneurysm; Endovascular technique; Circle of willis; Therapeutic embolization

\section{INTRODUCTION}

Since the report on the balloon-remodeling technique (BRT) by Moret et al.' for coiling complex cerebral aneurysms, the utility of balloons in neurointerventional procedures has expanded widely. In addition to its use in aneurysm treatment, balloons have been used in the management of cerebral vasospasm after subarachnoid hemorrhage, for controlled injection of liquid embolic agents in the treatment of cerebral arteriovenous mal- formations (AVMs), to assist in the proper apposition of a flow diverter to the vessel wall, and for venous sinus protection in the embolization of a dural AVM, just to name a few examples. ${ }^{2-4}$ Balloons have also been used to assist in the navigation of microcatheters across difficult vascular anatomy in the treatment of aneurysms and dural and pial AVMs. ${ }^{5-7}$ In this report, we describe endovascular coiling in 2 cases of wide-necked aneurysms where a balloon was used to aid in the navigation of a remodeling balloon. Further,

\section{Correspondence to:}

Madan Mohan Balaguruswamy, MD, PDCC

Department of Neurointerventional Radiology, Royal Care Super Specialty Hospital, Neelambur, Coimbatore 641062, India

Tel: +91-9944235744

E-mail:drmadanb@gmail.com

Received: October 12, 2020

Revised: April 3, 2021

Accepted: April 11, 2021

Copyright $\odot 2021$ Korean Society of Interventional Neuroradiology

This is an Open Access article distributed under the terms of the Creative Commons Attribution Non-Commercial License (http://creativecommons.org/licenses/by-nc/4.0) which permits unrestricted non-commercial use, distribution, and reproduction in any medium, provided the original work is properly cited.

pISSN 2093-9043 eISSN 2233-6273 
both cases had arterial fenestrations adjacent to the aneurysms, and their presence created challenges in the planning and execution of the BRT.

\section{CASE PEPORT}

\section{Case 1}

A 56-year-old male presented with an acute-onset headache. The Hunt-Hess grade was 3. Computed tomography
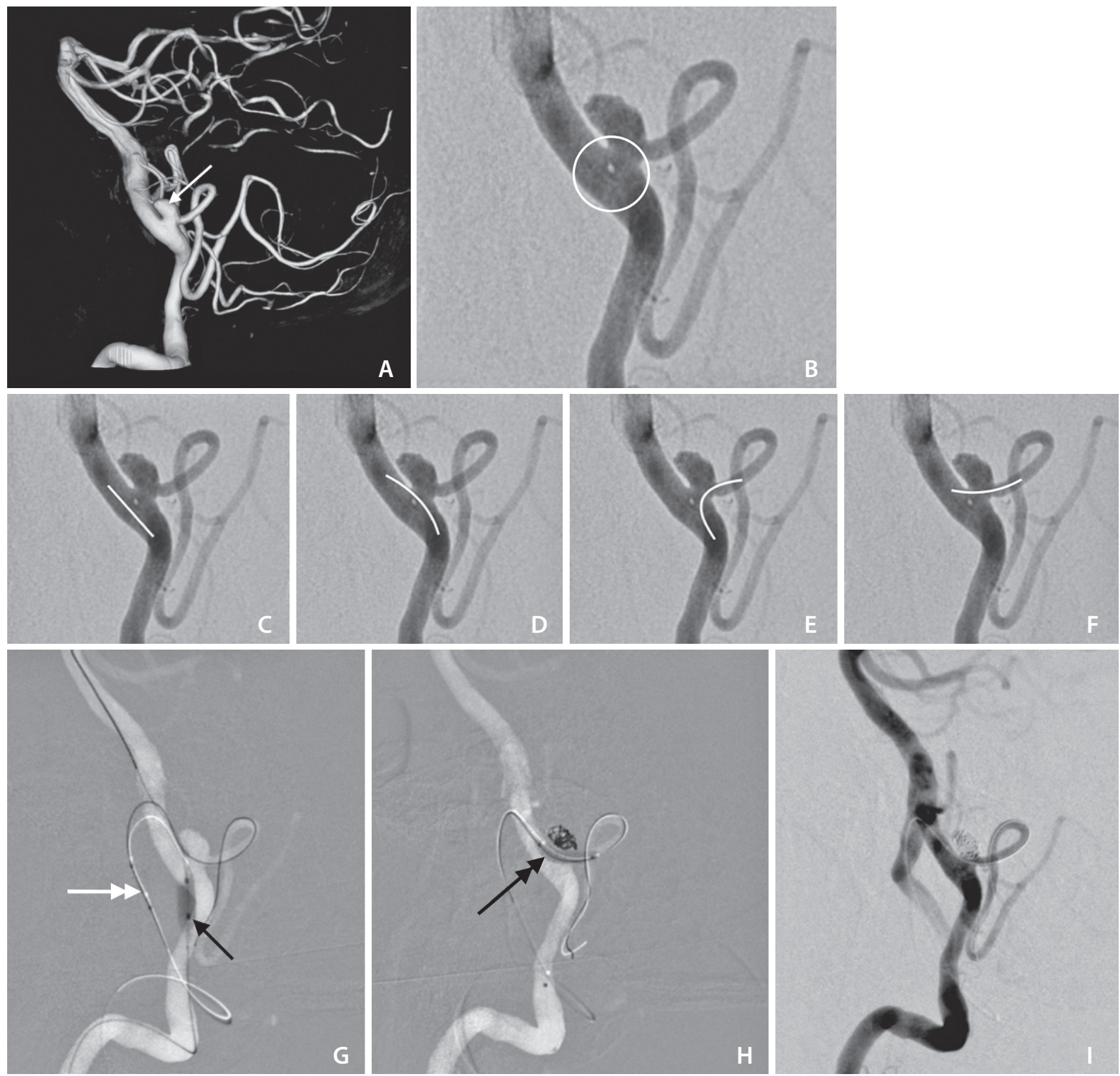

Fig. 1. (A) $3 D$ and (B) $2 D$ angiographic images of left VA reveal a wide-necked proximal PICA aneurysm (white arrow). A short fenestration is noted in the VA at the level of PICA origin (circle). (C-F) Four balloon options are shown as 'white line' on 2D image of the PICA aneurysm. (G) The inflated Apollo 4×10 balloon dilatation catheter (black arrow). The Transform 4×10 balloon (double-headed white arrow) in the right vertebral artery with the distal end of the balloon wire in the left PICA. (H) Aneurysm is partially coiled with the inflated Transform balloon (double-headed black arrow). (I) Final angiogram reveals Grade 1 occlusion of the aneurysm. VA, vertebral artery; PICA, posterior inferior cerebellar artery; DSA, digital subtraction angiography. 
(CT) revealed subarachnoid hemorrhage (modified CT Fisher grade 3) with blood predominantly in the left cerebellopontine and cerebellomedullary cisterns. Digital subtraction angiography, including 3D rotational angiography, revealed the presence of a wide-necked proximal posterior inferior cerebellar artery (PICA) aneurysm on the left side (Fig. 1A). The V4 segment of the left vertebral artery (VA) at the level of PICA origin revealed a fenestration (Fig. 1B).

The patient was prepared for endovascular coiling. A 6F long sheath and a DAC 057 catheter (Stryker Neurovascular, Fremont, CA, USA) were placed in the left VA through right femoral artery access. The balloon-remodeling technique was chosen after initial attempts at simple coiling resulted in repeated prolapse of the coils into the PICA origin. Various balloon configurations in relation to the $\mathrm{V} 4$ segment of vertebral artery fenestration were considered (Fig. 1C-F). After attempts to navigate the balloon into PICA from the ipsilateral VA failed, as illustrated in Fig. 1E, the plan was revised to place the balloon horizontally across the neck of the aneurysm (as in Fig. 1F). The right brachial artery was accessed, and a 5F Envoy catheter (Cordis Neurovascular, Miami Lakes, FL, USA) was placed in the right VA. A Transform 4×10 compliant balloon (Stryker Neurovascular) with Synchro 2 soft wire (Stryker Neurovascular) was advanced into the right VA and retrogradely into the left VA. After multiple failed attempts to navigate the balloon into the left PICA, a 4×10 Apollo balloon dilatation catheter (Brosmed Medical, Dongguan, China) was advanced antegradely in the left VA just below the level of PICA origin. The inflated Apollo balloon helped to deflect the Transform balloon into the PICA (Fig. 1G, H). The left VA Apollo balloon was then removed, and a Headway 17 microcatheter (Microvention Terumo, Aliso Viejo, CA, USA) was advanced into the aneurysm. Coiling of the aneurysm was done using the BRT to achieve Grade 1 occlusion (Fig. 11) of the aneurysm (Consensus Grading scale, Meyers et al. ${ }^{8}$ ). The patient was discharged 2 weeks later with no residual neurological deficits. A follow-up MR angiogram at 6 months revealed no aneurysm residue.
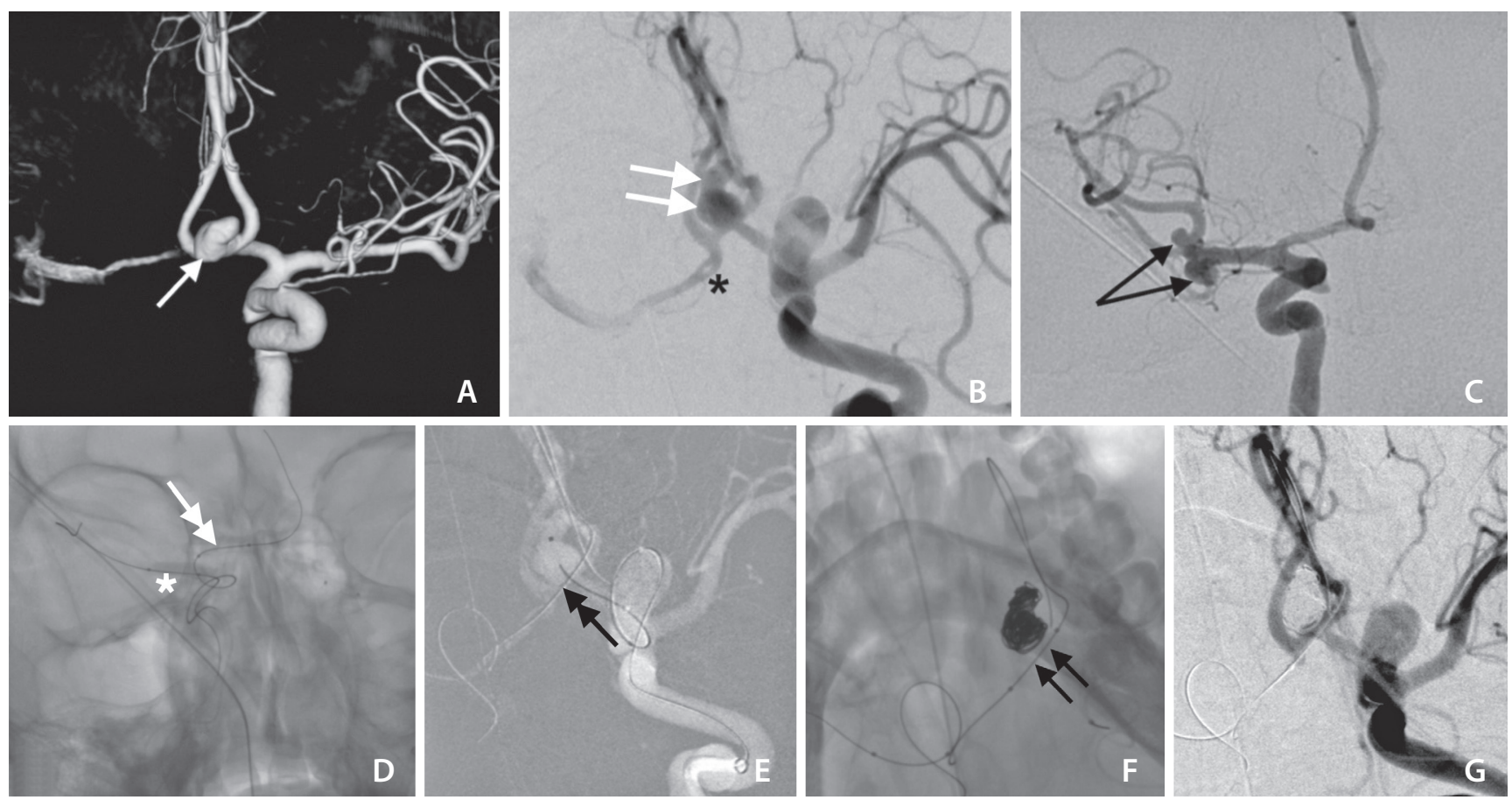

Fig. 2. (A) $3 D$ and (B) $2 D$ angiographic images in working projection reveal a wide-necked $A C o A$ aneurysm (white arrow in $\mathbf{A}$ and white double arrows in B). (B) Fenestration noted in right A1-ACA (black asterisk). (C) Right ICA angiogram in frontal projection shows two saccular aneurysms in the right MCA bifurcation (black arrows). (D) First Transform balloon (inflated) in right M1-MCA (white asterisk) and the second Transform balloon (double-headed white arrow) in right A1-ACA with the balloon wire in ACOA and left A2-ACA. (E) Working projection image with coiling microcatheter in the aneurysm and second balloon across aneurysm neck (black double arrowhead). (F) Coil mass in the aneurysm and Transform balloon across aneurysm neck (black double arrows). (G) Final angiogram reveals Grade 0 occlusion of the aneurysm. ACoA, anterior communicating artery; ACA, anterior cerebral artery; ICA, internal carotid artery; MCA, middle cerebral artery. 


\section{Case 2}

A 60-year-old female presented with an acute-onset headache and an episode of loss of consciousness. Her HuntHess grade was 2. CT revealed subarachnoid hemorrhage (modified CT Fisher grade 2). Cerebral angiography revealed a wide-necked anterior communicating artery (ACOA) aneurysm (Fig. 2A, B). The A1 segment of the right anterior cerebral artery (ACA) was relatively hypoplastic and revealed a fenestration. Both limbs of the fenestration appeared to be of equal diameter (Fig. 2B). The diameters of the fenestration limbs were measuring 0.92 to $0.95 \mathrm{~mm}$ each. Angiography also revealed 2 unruptured middle cerebral artery (MCA) bifurcation aneurysms (Fig. 2C). The patient was on long-term steroids for nephrotic syndrome.

The patient was prepared for coiling. As the wide-necked aneurysm morphology made it unsuitable for simple coiling we planned a BRT. The following strategies were considered: 1) navigating a balloon via the ipsilateral (left) internal carotid artery (ICA) into either the ipsilateral or contralateral A2 segment, 2) parallel balloon placement using a transcirculation approach with a balloon through the right A1 segment and coiling microcatheter through left A1 segment, and 3) using a double-balloon strategy with balloons navigated through ipsilateral ICA. We felt that the first strategy would not provide complete neck protection as the aneurysm neck incorporated both the ACOA and the proximal left A2 segment. The second strategy of parallel balloon placement, which involved placement of a balloon from the right A1 segment into the left A2 segment across the ACoA aneurysm neck, seemed to provide more complete neck coverage. Although the right $\mathrm{A} 1$ fenestration raised concerns regarding the ease of navigation of the balloon we decided to proceed with the transcirculation technique. The plan was to switch to the double-balloon strategy if the transcirculation technique failed. A 6F long sheath and DAC 057 were placed in the right ICA and a Transform 4×10 compliant balloon with a Synchro 2 soft wire was advanced into the right ICA. The acute angle of origin of the right A1 segment (Fig. 2C) made navigation of the balloon into the ACA impossible. The Transform balloon and the DAC 057 were removed. The Transform $4 \times 10$ balloon was then advanced through the $6 \mathrm{~F}$ long sheath and placed in the right proximal M1 segment, and a second Transform $4 \times 10$ compliant balloon was navigated into the right ICA. With the M1 segment balloon inflated, the second balloon catheter was navigated into the right A1 segment and further through the ACOA into the left A2 segment
(Fig. 2D). Spasm in the fenestration limb through which the balloon had passed created hurdles in balloon advancement. The spasm was relieved by infusion of nimodipine in the flush line connected to the long sheath. The balloon was positioned horizontally across the neck of the aneurysm (Fig. 2E). Through a 6F Envoy catheter placed in the left ICA, an Echelon-10 microcatheter (Medtronic, Irvine, CA, USA) was advanced into the aneurysm, and coiling of the aneurysm was done using the BRT. Final angiograms revealed Grade 0 occlusion of the aneurysm (Consensus grading scale) (Fig. 2F, G).

The patient recovered from the procedure without any complications but eventually succumbed 12 days later to complications of sepsis contributed by her immunocompromised status (nephrotic syndrome and long-term steroid use).

\section{DISCUSSION}

The balloon-remodeling technique is an invaluable tool in the armamentarium of a neurointerventionist. Pierot et al. ${ }^{9}$ described the various configurations of placement of balloon with respect to the aneurysm neck. The technique of parallel placement of a balloon, where the orientation of the coiling microcatheter and the balloon microcatheter are perpendicular to each other, was used in both of our cases. With regard to the vascular arrangement of both of our cases, this technique appeared to have the following advantages: 1) complete coverage of the aneurysm neck and 2) reduced risk for aneurysm rupture during balloon navigation due to the parallel trajectory of the balloon.

Dual access and a transcirculation approach are usually needed to achieve placement of a balloon in a parallel configuration in bifurcation aneurysms. The transcirculation approach involves the navigation of a device from the anterior circulation to posterior circulation (or vice versa) or from right side to left side (or vice versa). ${ }^{10}$ Moret et al. ${ }^{11}$ called it the retrograde approach. The transcirculation approach using a balloon and/or stent assistance for the endovascular management of complex aneurysms has been reported for aneurysms involving ICA bifurcation, basilar tip, superior cerebellar artery, PICA, and ACOA. ${ }^{10,12}$ In case 1, the balloon was navigated from the right vertebral artery to the contralateral vertebral artery. In case 2, the balloon was navigated from the right $A 1$ segment of the ACA to the left $A 2$ segment through the ACOA. Transcirculation techniques are valuable 
in the management of complex aneurysms. However, these procedures can be technically challenging and time-consuming and have the potential to introduce risks into a circulation that does not harbor a pathology. In case 2, this risk was increased by the presence of the 2 unruptured MCA aneurysms.

Balloons are less navigable compared to microcatheters, and navigating them across difficult angulations can be challenging. Several strategies have been reported in the literature for navigating balloons across difficult vascular angles. Most of the described techniques are for catheterizing recurrent branches in bifurcation aneurysms. ${ }^{13-16}$ Relevant to the cases described are 2 such techniques - the 'Exchange maneuver' technique and the 'Sheeping technique' described by Chapot et al. ${ }^{14}$ With the Exchange maneuver technique, the microcatheter is first navigated across the tortuous anatomy and is exchanged for a remodeling balloon over an exchange wire. With the Sheeping technique, the placement of a microcatheter over microwire inside the artery requiring balloon protection creates a favorable angle between the proximal and distal artery; and this favorable angle is used by the balloon catheter for easy navigation. The success of both techniques depends on the successful initial placement of a microcatheter. Further, exchange maneuvers with microwire tips in small arteries can introduce the risk of vessel perforations. The strategy employed in our cases may be used when balloon navigation occurs through arteries with small diameters. Small arteries, like the PICA and the fenestrated A1 segment in our cases, can make exchange maneuvers and sheeping techniques difficult and risky. Using balloons to deflect the course of a microcatheter has been described earlier for treatment of pial AVMs, dural AVMs, and aneurysm coiling. $^{5-7}$ The use of a second balloon helped in reducing procedure time and thereby radiation dose. Although successful in our case, the procedure is not without its risks, and caution is advised. In our limited experience with this technique, we have not encountered any complications but there is always the possibility of balloon-induced dissection and thromboembolic complications, and the additional costs involved also need to be considered. In one or both of our cases, a stent-assisted coiling technique could have been chosen as an alternative to the BRT. But we were wary of the higher complication rates that are known to occur with the use of stents in ruptured aneurysms. ${ }^{17}$ We routinely reserve stents for situations where the balloon fails or is expected to fail.
Another feature common to both cases was the presence of arterial fenestrations adjacent to the aneurysms. Cerebral arterial fenestrations are segmental duplications of arteries into 2 distinct endothelium-lined channels. The entity manifests due to the failure of fusion of paired embryological arteries. $^{18}$ Fenestrations may be associated with an increased risk of adjacent aneurysm formation. ${ }^{19}$ In both our cases, the fenestrations were located adjacent to the aneurysm and their presence affected the balloon-navigation options. In case 1, the various possible balloon positions were dictated by the VA fenestration as illustrated earlier (Fig. 1D, F). In case 2, a spasm in a fenestration limb due to the passage of the remodeling balloon caused a delay in its advancement. Fenestrations can also offer innovative solutions for aneurysm treatment, as in the case described by Morrison et al where a stent was navigated circumferentially from one limb of fenestration to the other limb. ${ }^{20}$

Balloon-assisted navigation of devices is a very useful technique when performing neurointerventional procedures. This, and the transcirculation coiling technique, widens the scope of the neurointerventionist and allows more procedures to be performed successfully using the endovascular route.

\section{Fund}

None.

\section{Ethics Statement}

Informed consent was obtained from the patient and/or patient representative to use clinical information and images for the preparation of this manuscript. Institutional review board approval was not required for this case report.

\section{Conflicts of Interest}

The authors have no conflicts to disclose.

\section{Author Contributions}

Concept and design: MMB, EM, KV, CSJ, and KM. Writing the article: MMB. Critical revision of the article: MMB, EM, KV, CSJ, and KM. Final approval of the article: MMB, EM, KV, CSJ, and KM. Overall responsibility: MMB.

\section{ORCID}

Madan Mohan Balaguruswamy:
https://orcid.org/0000-0002-3832-9819
Ezaz Mohamed: https://orcid.org/0000-0003-1214-9999 
Krishnan Vijayan: https://orcid.org/0000-0002-2836-2877

Chaitanya S Juluri: https://orcid.org/0000-0003-0777-5645

Karuppannaswamy Madeswaran:

https://orcid.org/0000-0002-5264-4233

\section{REFERENCES}

1. Moret J, Cognard C, Weill A, Castaings L, Rey A. The "remodelling technique" in the treatment of wide neck intracranial aneurysms. Angiographic results and clinical follow-up in 56 cases. Interv Neuroradiol 1997;3:21-35

2. Alaraj A, Wallace A, Dashti R, Patel P, Aletich V. Balloons in endovascular neurosurgery: history and current applications. Neurosurgery 2014;74 Suppl 1:S163-S190

3. Shi ZS, Loh Y, Duckwiler GR, Jahan R, Viñuela F. Balloon-assisted transarterial embolization of intracranial dural arteriovenous fistulas. J Neurosurg 2009;110:921-928

4. Rajah G, Narayanan S, Rangel-Castilla L. Update on flow diverters for the endovascular management of cerebral aneurysms. Neurosurg Focus 2017:42:E2

5. Zhao WY, Krings T, Yang PF, Liu JM, Xu Y, Li Q, et al. Balloon-assisted superselective microcatheterization for transarterial treatment of cranial dural arteriovenous fistulas: technique and results. Neurosurgery 2012;71(2 Suppl Operative):ons269-273

6. Mendes GA, Silveira EP, Saleme S, losif C, Ponomarjova S, Caire F, et al. Balloon-assisted microcatheter navigation for AVM embolization: technical note. J Neurosurg 2015;123:1120-1124

7. Mahajan A, Goel G. Endovascular treatment of distal lenticulostriate artery aneurysm by selective catheterization of artery with balloon-blocking technique: 2-dimensional video illustration. World Neurosurg 2020;136:220

8. Meyers PM, Schumacher HC, Higashida RT, Derdeyn CP, Nesbit GM, Sacks D, et al. Reporting standards for endovascular repair of saccular intracranial cerebral aneurysms. Stroke 2009;40:e366-e379

9. Pierot L, Cognard C, Spelle L, Moret J. Safety and efficacy of balloon remodeling technique during endovascular treatment of intracranial aneurysms: critical review of the literature. AJNR Am J Neuroradiol 2012;33:12-15
10. Albuquerque FC, Gonzalez LF, Hu YC, Newman CB, McDougall CG. Transcirculation endovascular treatment of complex cerebral aneurysms: technical considerations and preliminary results. Neurosurgery 2011;68:820-829

11. Moret J, Ross IB, Weill A, Piotin M. The retrograde approach: a consideration for the endovascular treatment of aneurysms. AJNR Am J Neuroradio/ 2000;21:262-268

12. Heye S, Stracke CP, Nordmeyer H, Heddier M, Stauder M, Chapot R. Retrograde access to the posterior inferior cerebellar artery in balloon-assisted coiling of posterior inferior cerebellar artery aneurysms. J Neurointerv Surg 2015;7:824-828

13. Cekirge SH, Yavuz K, Geyik S, Saatci I. HyperForm balloon-assisted endovascular neck bypass technique to perform balloon or stent-assisted treatment of cerebral aneurysms. AJNR Am J Neuroradio/ 2007;28:1388-1390

14. Chapot R, Nordmeyer $H$, Heddier M, Velasco A, Schooss P, Stauder $M$, et al. The sheeping technique or how to avoid exchange maneuvers. Neuroradiology 2013;55:989-992

15. Wolfe SQ, Farhat H, Moftakhar R, Elhammady MS, Aziz-Sultan MA. Intraaneurysmal balloon assistance for navigation across a wide-necked aneurysm. J Neurosurg 2010;112:1222-1226

16. Ito H, Onodera H, Wakui D, Uchida M, Sase T, Morishima H, et al. The "temporary caging" technique for catheter navigation in patients with intracranial wide-necked aneurysms. Int J Clin Exp Med 2015;8:11214-11219

17. Bechan RS, Sprengers ME, Majoie CB, Peluso JP, Sluzewski M, van Rooij WJ. Stent-assisted coil embolization of intracranial aneurysms: complications in acutely ruptured versus unruptured aneurysms. AJNR Am J Neuroradiol 2016;37:502-507

18. Dey M, Awad IA. Fenestration of supraclinoid internal carotid artery and associated aneurysm: embryogenesis, recognition, and management. World Neurosurg 2011;76:592.e1-592.e5

19. Guo X, Gao L, Shi Z, Liu D, Wang Y, Sun Z, et al. Intracranial arterial fenestration and risk of aneurysm: a systematic review and meta-analysis. World Neurosurg 2018;115:e592-e598

20. Morrison J, Alexander MD, Dowd CF, Cooke DL. Flanking the fenestration: circumferential limb-to-limb stent-assisted coiling of a basilar artery fenestration aneurysm. J Neurointerv Surg 2018;10:e12 